\title{
Oil and gas well rate estimation by choke formula: semi-analytical approach
}

\author{
Mohammad Ali Kargarpour ${ }^{1}$ (D)
}

Received: 19 November 2018 / Accepted: 16 February 2019 / Published online: 11 March 2019

(c) The Author(s) 2019

\begin{abstract}
During last decades accurate two-phase flow meters are introduced to upstream oil and gas industry; however, due to economic and technical issues, the use of choke formula for estimating well production rate is still popular. After its first introduction by Gilbert (Flowing and gas-lift well performance. API Drilling Production Practice 20:126-157, 1945), several other formulas were developed, either with global purposes or targeting a specific reservoir. All of these Gilbert-type choke formulas assume sonic flow conditions through a well head choke; for this reason, they do not consider the differential pressure across the choke. The other types of choke formulas which are introduced by some pioneer researchers (Fortunati, Two-Phase Flow Through Wellhead Chokes. Paper SPE 3742, 1972; Ashford, Pierce, The Determination of Multiphase Pressure Drops and Flow Capacities in Downhole Safety Valves, JPT, September, 1974) consider the subsonic velocity condition through the choke at expense of formula complication. Field experience reveals that there are cases in which the well flow rate is changed by changing the downstream separator operation pressure. In this paper, by using basic concepts of fluid mechanics, it is shown that the rate of two-phase flow through a choke generally depends on the pressure drop across the choke besides other factors by deriving a global choke formula. Based on this finding, a general Gilbert-type choke formula is derived which includes differential pressure across the choke. This new choke formula is validated using a field data bank including 399 data points.
\end{abstract}

Keywords Choke formula $\cdot$ Sonic flow $\cdot$ Subsonic flow $\cdot$ Well rate $\cdot$ Pressure drop across choke $\cdot$ Two-phase flow

\section{Introduction}

In last decades, by using advanced technology, different types of so-called accurate two-phase flow meters are introduced to oil and gas industries. By utilizing these two-phase flow meters on the well heads or manifolds, it was expected that exact amount of oil, gas, and water produced from each individual well to be calculated; however, in addition to inherent errors in this category of meters, due to economic issues (both Capital Expenditure, CAPEX and Operational Expenditure, OPEX) they are not broadly employed, yet. On the other hand, for dynamic reservoir management having production data from each well to some level of reliability is very important. So, using the empirical choke formula for estimating well rate is still common. For this reason,

Mohammad Ali Kargarpour

kargarpour2000@yahoo.com; makargarpour@alaska.edu

1 Department of Petroleum Engineering, Petroleum Engineering and Development Company, Tehran, Iran since first such formula introduced by Gilbert (1954), several authors tried to generate formulas and equations for estimating the fluid flow rate through the well head chokes. The published choke formulas can be divided into two large categories: simple and complicated formulas. The simple formulas are also called Gilbert-type equations. In this type of formulas, fluid flow rate of well is related to upstream choke pressure, ' $P_{1}$ '; gas-oil ratio, 'GOR'; and internal choke size diameter, ' $d$ '. Among other of this type of choke formulas, the Gilbert (1954), Ros (1960), Achong (1961), and Baxendall (1961) are more popular. The general form of this category is presented as (Guo et al. 2007)

$q=a \frac{P_{1} d^{b}}{\mathrm{GOR}^{c}}$,

where ' $q$ ' is liquid rate, ' $P_{1}$ ' upstream pressure, ' $d$ ' and 'GOR' as defined above, and ' $a$ ', ' $b$ ', and ' $c$ ' are empirical constants which should be estimated by fitting the formula to the available measured data. In Gilbert formula, constants 'a', 'b', and 'c' are $0.1,1.89$ and 0.546 , respectively. 
If one wishes to name investigators who work on this type of choke formula, a long list of authors and equations can be provided. Bairamzadeh and Ghanaatpisheh (2015) used about 1500 data points from 120 oil producer wells to regress the empirical constants of a choke equation similar to Eq. 1. In their equation, the exponent coefficient of pressure is not equal to one. Ganat and Hrairi (2018) used a methodology to predict the flow of wells which are equipped and flow with electrical submersible pump (ESP). Giacchetta et al. (2014) numerically investigated two-phase flow of hydrocarbons fluids through an orifice under critical conditions.

To increase the accuracy of choke formula, several authors tried to use the concepts of two-phase flow; so, they introduced more complicated choke formula. Among this group of researchers, one can mention Ashford and Pierce (1974), Sachdeva et al. (1986), Perkins (1993) and Fortunati (1972). Brill and Mukherjee (1999), Buffa and Baliño (2017) and Ruston et al. (1997) reviewed details of this type of choke formulas. All of this type of formulas using a set of equation to estimate well flow rate passing through a well head choke. It is expected that this choke formula category to be more accurate at the expense of complexity. Complexity of this type of choke formulas decreased popularity of them among petroleum field engineers.

Although, all types of choke formulas have inherent errors and they are not reliable for situations which require accurate rate calculation; however, they are widely employed for well rate estimation in the field and in the reservoir management for estimation history rates of wells and reservoirs. Applicability of a choke formula highly depends on its accuracy and simplicity. Among the 'simple'-type choke formulas, Gilbert formula shows more accurate results (Al-Attar and Abdul-Majeed 1988; Al-Attar 2010). In this study, the Gilbert formula is also tested by available 399 data points (Fig. 1) and the results indicate a relative error in the range of -97 to +56 . No filtering applied on the data set. Some of the information in this data set seems to be erroneous, especially in reported GOR values.

It is considered that the simple choke formulas estimate the oil well rate in 'critical' or 'sonic' flow conditions based on the work of Tangren et.al. (1949) (Guo et al. 2007). Based on the laboratory activities and performed tests on the water and gas, Tangren et al. (1949) claimed that a gas-water mixture acts as a compressible fluid when passes through the 'de Laval nozzle' (Guo et al. 2007). Using this concept for chokes in actual field conditions is under question. Single-phase gas stream would reach to sonic velocity when the downstream to upstream pressures $\left(P_{2} / P_{1}\right)$ of choke (or any other restriction) is equal or less than about 0.55 , depending on the specific heat ratio $(k)$. The critical pressure drop across a restriction for single-phase gas is defined by following equation (Brill and Mukherjee 1999; Guo et al. 2007):

$\frac{P_{\text {downstream }}}{P_{\text {upstream }}}=\frac{P_{2}}{P_{1}}=\left(\frac{2}{1+k}\right)^{\frac{k}{1-k}}$.

The magnitude of $P_{2} / P_{1}=0.55$ is obtained by considering the average $\mathrm{k}$-value for natural gases to be equal to 1.28 (Guo et.al. 2007). By the presence a few amount of liquid (condensate and/or water), it is difficult to accept
Fig. 1 Comparison of estimated oil well rate (Gilbert's equation) with measured rate

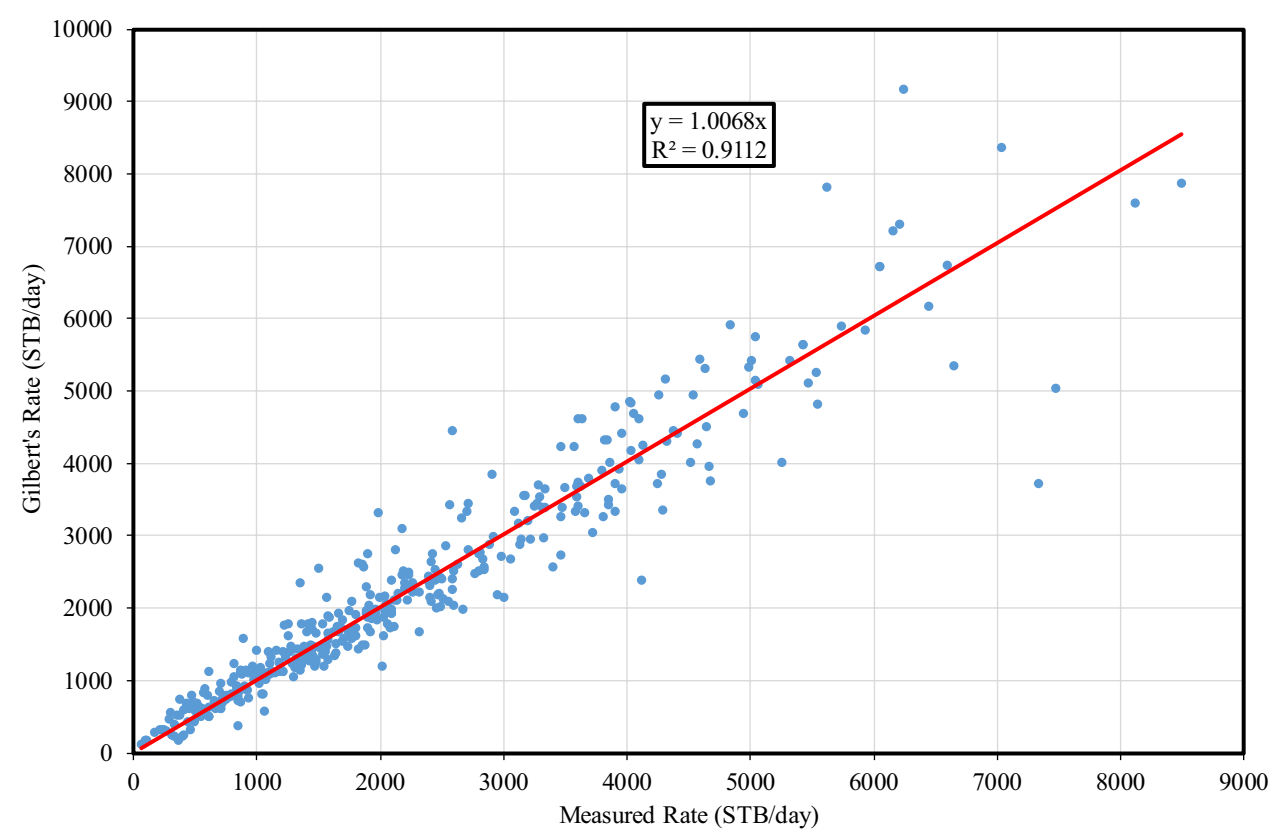


that the fluid stream acts similar to single-phase gas. However, based on this concept (that the two-phase fluid also reaches to 'critical', sonic, conditions) in the Gilberttype equation for choke, pressure drop across the choke is ignored. Author's experience showed that flowing the well to different separators with different operating pressures would affect the flow rate though the choke. In the following sections, by deriving choke formulas for single-phase gas and single-phase liquid, a two-phase flow choke formula is derived including differential pressure drop across the choke. The derived two-phase flow choke formula is then tested against the measured data set.

\section{Procedure}

\section{Sonic single-phase gas flow}

In appendix ' 1 ' by using the basic formula for sonic velocity in the materials and assuming isentropic conditions through the choke, the following choke formula for single-phase gas flow is obtained:

$Q_{\text {acfd }}=19523 \times d^{2} \sqrt{\frac{Z k T}{G}}$,

where ' $Q_{\text {acfd }}$ ', ' $d$ ', ' $z$ ', ' $k$ ', ' $T$ ', and ' $G$ ' are actual gas flow rate in cubic feet per day (cfd), choke size in inches, gas compressibility factor (dimensionless), specific heat ratio (dimensionless), gas temperature in degree Rankine $\left({ }^{\circ} \mathrm{R}\right)$ and gas specific gravity with respect to air, respectively. Using the equation of state for real gases and considering some average values for gas compressibility factor, specific heat ratio, gas temperature and gas specific gravity, the following choke formula for single-phase gas flow is derived (Equation 38, Appendix 1):

$\mathrm{Q}_{\text {scfd }}=40997 \times P d^{2}$.

By recalling the 'vena contracta' phenomenon in orifice flow metering, a factor of o.6 is introduced in Eq. (4); so, the final choke formula for single-phase gas flow is as follows:

$\mathrm{Q}_{\text {scfd }}=24598 \times P d^{2}$.

In Eq. (5), ' $\mathrm{Q}_{\text {scfd }}$ ', ' $P$ ', and 'd' are gas flow rate in standard cubic feet per day (scfd), upstream choke pressure in pound per squired inch (psi) and is choke size in inches, respectively. Note that in practical engineering purposes, the constant in Eq. (5) is considered to be in the range of 19,000-26,000 depending on the gas conditions and specifications.
Equation (5) is valid when:

$\frac{P_{\text {downstream }}}{P_{\text {upstream }}}=\frac{P_{2}}{P_{1}} \leq\left(\frac{2}{1+k}\right)^{\frac{k}{1-k}} \leq 0.55$.

\section{Subsonic single-phase gas flow}

In Appendix '2', by adopting the concept of gas mass flow from basic concepts of fluid mechanics (Streeter 1962; White 2011) and, employing the average values for some gas specifications and the concept of discharge coefficient from orifice flow metering, the following formula is derived for subsonic single-phase gas flow:

$q_{\text {scfd }}=65554 \times d^{2} P_{1} \sqrt{\left(\frac{P_{2}}{P_{1}}\right)^{1.5625}\left[1-\left(\frac{P_{2}}{P_{1}}\right)^{0.21875}\right]}$.

All variables in Eq. (6) are defined as above.

\section{Choked flow conditions for liquids}

In Appendix ' 3 ' by using the basic equation for sonic velocity in the materials and combining with Bernoulli's equation, it is concluded that for having a sonic single-phase liquid flow in a restriction (choke), the pressure drop across the restriction should be equal to or greater than ' $\mathrm{B} / 2$ ', where ' $\mathrm{B}$ ' is modulus of elasticity of liquid. Batzle and Wang (1992) estimated the bulk modulus of elasticity of some crudes in the range of $217,500-375,000 \mathrm{psi}(1500-2500 \mathrm{MPa})$. It means that to have choking conditions across a choke in crude oil pipelines, the differential pressure across choke should be more than hundreds thousands of psi!

\section{Choke for two-phase (gas and liquid) flow}

In appendix ' 4', it is assumed that part of area of choke is occupied by gas stream and liquid flows in the rest. In mathematical form, it is written:

$A_{\mathrm{t}}=A_{\mathrm{g}}+A_{\mathrm{l}}$,

where ' $A_{\mathrm{t}}$ ', ' $A_{\mathrm{g}}$ ', and ' $A_{1}$ ' are total cross-sectional area of choke, assumed area available for gas flow, and assumed area available for liquid flow, respectively. By utilizing Bernoulli's equation for liquid flow and Eq. (6) for gas flow and substituting them in Eq. (7), the following equation is 
generated as a general form of choke formula for estimating the liquid flow rate in two-phase fluid flow:
(Eq. 8) is divided into two equations; use Eq. (8) for ' $P_{2} / P_{1}$ ' greater than 0.55 and use the following equation for ' $P_{2} / P_{1}$ '

$q_{\mathrm{BPD}}=P_{1} d^{2} \times\left\{\frac{\sqrt{P_{1}}}{552 \times \sqrt{\frac{\left(1-\frac{P_{2}}{P_{1}}\right)}{\mathrm{Spr}}}}+\frac{\text { GOR }}{65554 \times \sqrt{\left(\frac{P_{2}}{P_{1}}\right)^{1.5625}\left[1-\left(\frac{P_{2}}{P_{1}}\right)^{0.21875}\right]}}\right\}^{-1}$,

where ' $q_{\mathrm{BPD}}$ ', ' $\mathrm{P}_{1}$ ', ' $\mathrm{S}_{\mathrm{P}} \mathrm{G}_{\mathrm{R}}$ ', and 'GOR' are well flow rate in stock tank barrel per day, upstream choke pressure in psi, liquid specific gravity respect to water, and gas/oil ratio in standard cubic feet per stock tank barrel, respectively. ' $\mathrm{P}_{2}$ ' $\mathrm{P}_{1}{ }^{\prime}$ is defined as before.

\section{Testing the generated two-phase flow choke formula}

A data bank consisting of 399 data points is prepared. These data are gathered from portable well test separator during Full Bore Drill Stem Tests (FBDSTs). The range of variables in this data bank is as follows:

API: $12.8-42$,

Upstream choke pressure, ' $\mathrm{P}_{1}$ ', (psi): 38-5538,

' $\mathrm{P}_{2} / \mathrm{P}_{1}$ ': 0.01-0.91,

'GOR', standard cubic feet per stock tank barrel, (scf/ stb): 61-6044,

Choke size (inches): 8/64-96/64.

Testing the new choke formula, shows some extra error when ' $P_{2} / P_{1}$ ' is less than 0.55 ; so, the general equation equal or less than 0.55 .

$q_{\mathrm{BPD}}=P_{1} d^{2} \times\left\{\frac{\sqrt{P_{1}}}{552 \times \sqrt{\frac{\left(1-\frac{P_{2}}{P_{1}}\right)}{\mathrm{SpGr}}}}+\frac{\mathrm{GOR}}{14387}\right\}^{-1}$.

Using Eqs. (8) and (9) and using average 'SpGr' (of oil) equal to 0.9 , the oil flow rate of data bank was estimated and compared with the actual measured oil rate (see Fig. 2).

The derived choke formula still seems a little complicated. To simplify it, it is tried to derive a Gilbert-type formula by keeping in mind that in addition to upstream choke pressure $\left(P_{1}\right)$, choke size $(d)$, and GOR $(R)$, the oil well flow rate also depends on differential pressure across the choke $(\Delta \mathrm{P})$. By looking at Eqs. (8), (9), and specially Equation (70) and some manipulations, it can be deduced that flow rate is in direct relation with $\Delta P$; so, the following form of choke formula was tested against the data bank:

$q=403 \frac{P^{0.41} \Delta P^{0.44} d^{2}}{R^{0.42}}$,
Fig. 2 Comparison of estimated oil well rate, Eqs. (8) and (9) with measured rate

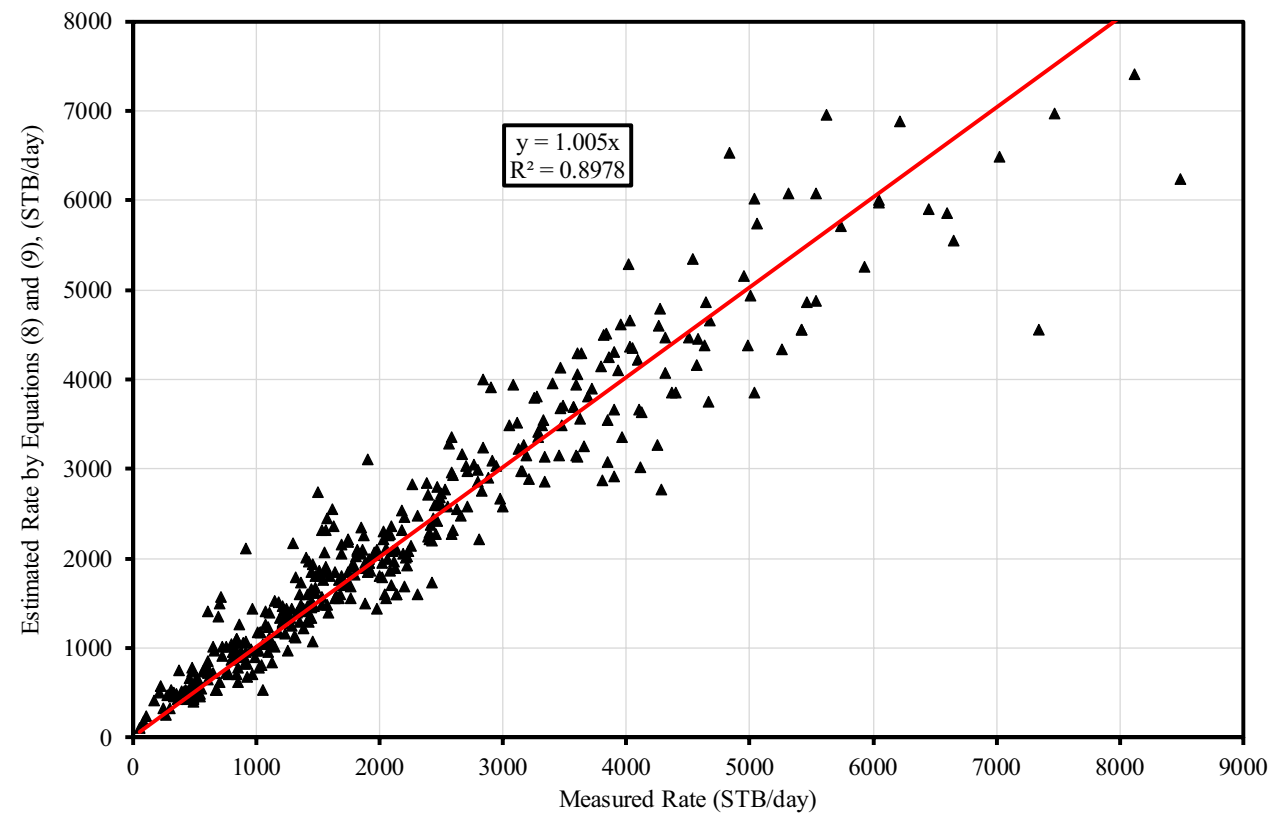


Fig. 3 Comparison of estimated oil well rate, Eq. 10, with measured rate

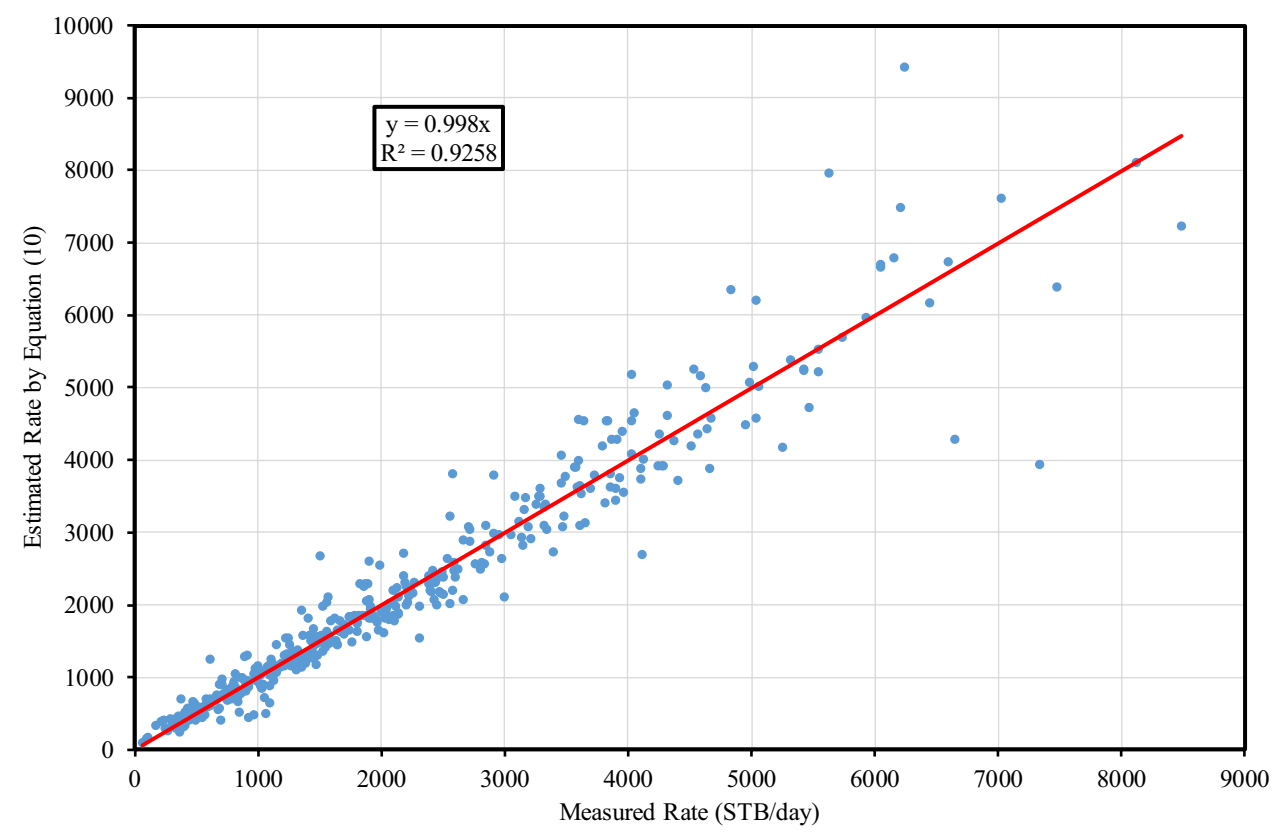

where ' $q$ ', ' $P$ ', ' $\Delta P$ ', ' $d$ ', and ' $R$ ' are well flow rate in STB/ day, upstream well flowing pressure in psi, differential pressure across choke in psi, choke size in inches, and 'GOR' in standard cubic feet per stock tank barrel, respectively. Comparison of estimated flow rate by Eq. (10) with measured flow rate is depicted in Fig. 3. The following equation is another form of Eq. (10) but unit of choke size diameter $(d)$ is in ' $1 / 64$ ' inches and the other variables have the same unit as Eq. (10).

$q=0.098 \frac{P^{0.41} \Delta P^{0.44} d^{2}}{R^{0.42}}$.
By some mathematical manipulation, Eq. (10) and Eq. (11) can be presented in the following forms:

$$
\begin{aligned}
& q=403 \frac{P^{0.85}\left(1-\left(P_{2} / P_{1}\right)^{0.44}\right) d^{2}}{R^{0.42}}, \\
& q=0.098 \frac{P^{0.85}\left(1-\left(P_{2 / P_{1}}\right)^{0.44}\right) d^{2}}{R^{0.42}} .
\end{aligned}
$$

Fig. 4 Effect of error in GOR on the error in calculated rate

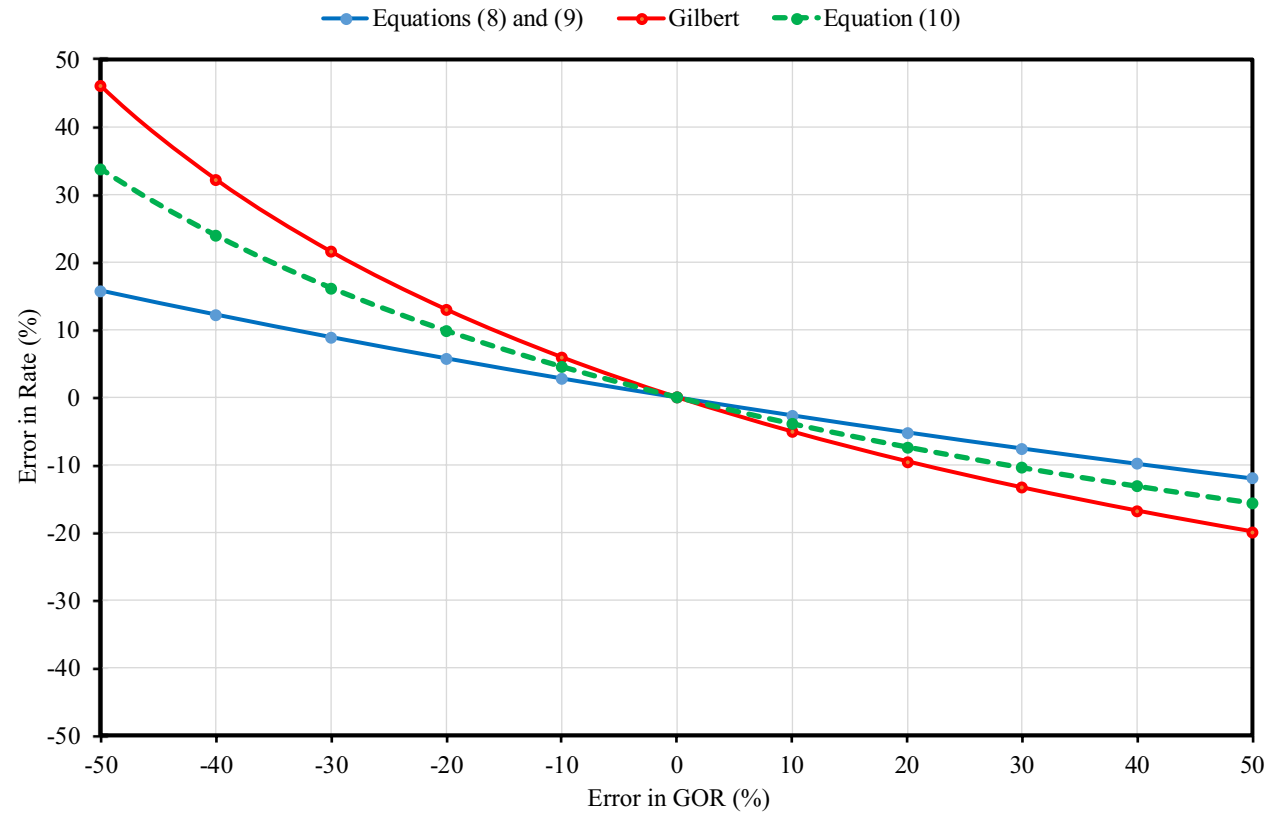


Fig. 5 Effect of error in a few variables on the error in calculated rate based on Eq. (10)

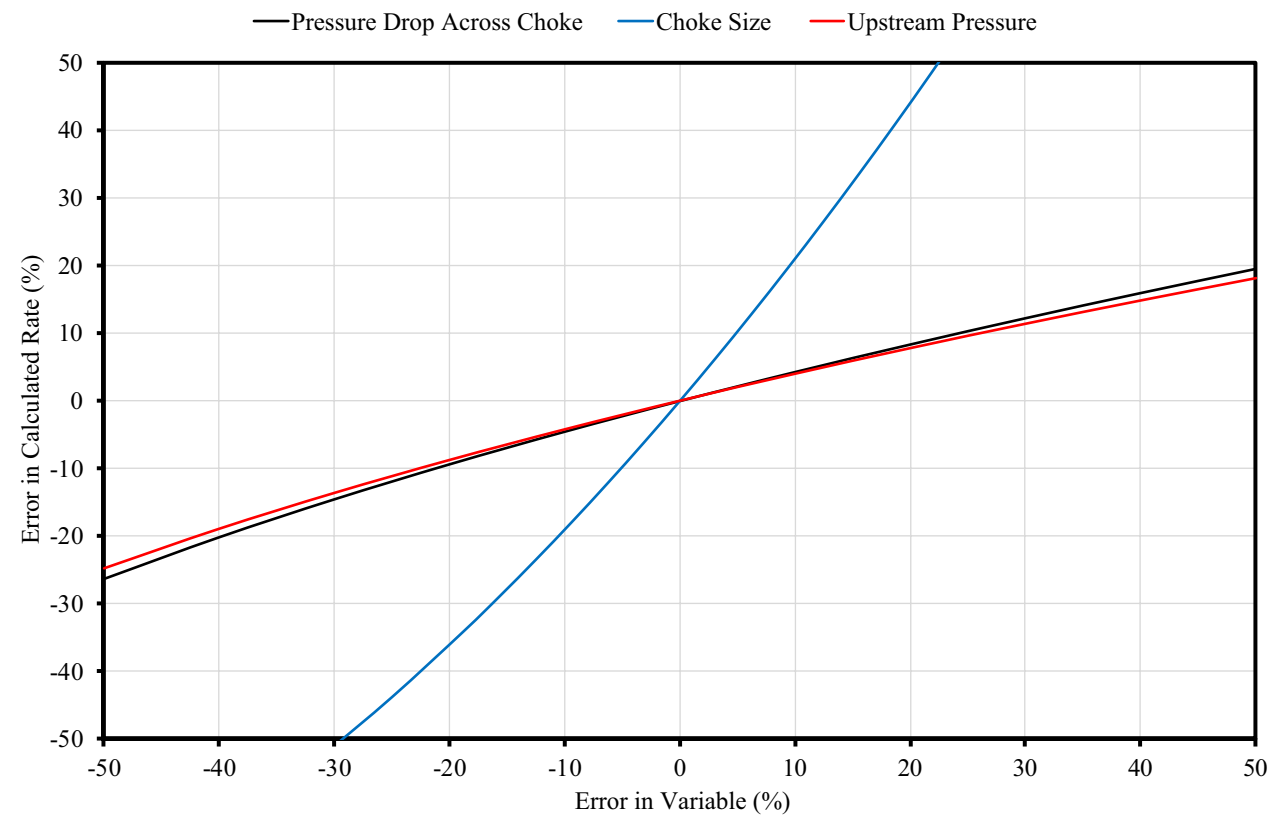

Figure 4 illustrates relative errors of Gilbert formula, Eq. (8), and Eq. (10) based on the information of the available data set.

\section{Discussion}

As it is mentioned, strictly speaking choke formula is not appropriate for well production rate calculation for any fiscal purposes; however, for engineering calculation purposes its accuracy is acceptable. The accuracy of each choke formula is in the range of variables' data which are utilized to derive it. For this reason, a wide group of researchers (a few of them are Elgibaly and Nashawi 1997; Beiranvand et.al. 2012; Sadiq 2012) tried to derive a unique choke formula for a special reservoir or a region. In this paper, a global choke formula is generated and validated by a set of unfiltered measured data points. Besides of inherent errors in measurement devices (gauge pressures, flow rate meters) and calculation procedures (for gas and liquid calculations), human error is one of the important errors in field operation. By examining Eq. (10) or (11) (Figs. 4, 5), it is revealed that $-20 \%$ error in reported GOR would cause an amount of $10 \%$ error in estimated flow rate. Also, just 3\% error in choke size diameter would result more than $6 \%$ error in rate. Also, simultaneous $10 \%$ error in measurement of both upstream pressure and pressure drop across the choke would impose about $10 \%$ error in estimated flow rate. These numbers indicate that measurement errors in reported values will cause a significant error in flow rate estimated by choke formula. On the other hand, it is difficult to find out the erroneous values in a data bank even using a reliable mathematical procedure.
In this paper, it is assumed that errors in the gathered data bank values would potentially, to some extent, cancel each other out; so, the data were not filtered.

Examining Fig. 4 which illustrates the effect of error in estimated well rate from choke formula indicates that the associated error of the new formula is less than that of by Gilbert formula when reported GOR is not correct. Note that the reported GOR values to some degrees are usually erroneous.

Prediction of two-phase flow performance in pipes and its fitting is very difficult. This is due to slip velocity between liquid and gas fluids. This phenomenon worsens in well head choke as gas and liquid intermittently flow through the choke. By passing live oil from pay zone through well production string and well head fittings, the associated gas is gradually separated due to mostly pressure drop. Slip velocity causes dynamic accumulation of gases in the passage. This means that liquid and gas flow through the well head choke with 'different ratios' even in one specific well and for a short period of time, say $1 \mathrm{~h}$. So, well fluid flow through the choke is practically an unsteady state flow. Unsteady state nature of flow through choke and requirement of the hundreds of thousands differential pressure for liquid flow to reach sonic velocity make it difficult to accept sonic two-phase flow through the well head choke for all practical conditions. The new derived Gilbert-type choke equation seems to be more realistic as it includes the pressure drop across the choke. Figure 6 depicts the comparison between this new choke formula and that of Gilbert, for the same set of data. In this comparison, the flowing well head pressure and choke size are considered to be equal to $600 \mathrm{psi}$ and 32/64", respectively. The calculations are made for three GOR cases $(400,600$, and $800 \mathrm{scf} / \mathrm{stb}$ ). As it is expected, the Gilbert formula just 
Fig. 6 Comparison of new choke formula with that of Gilbert

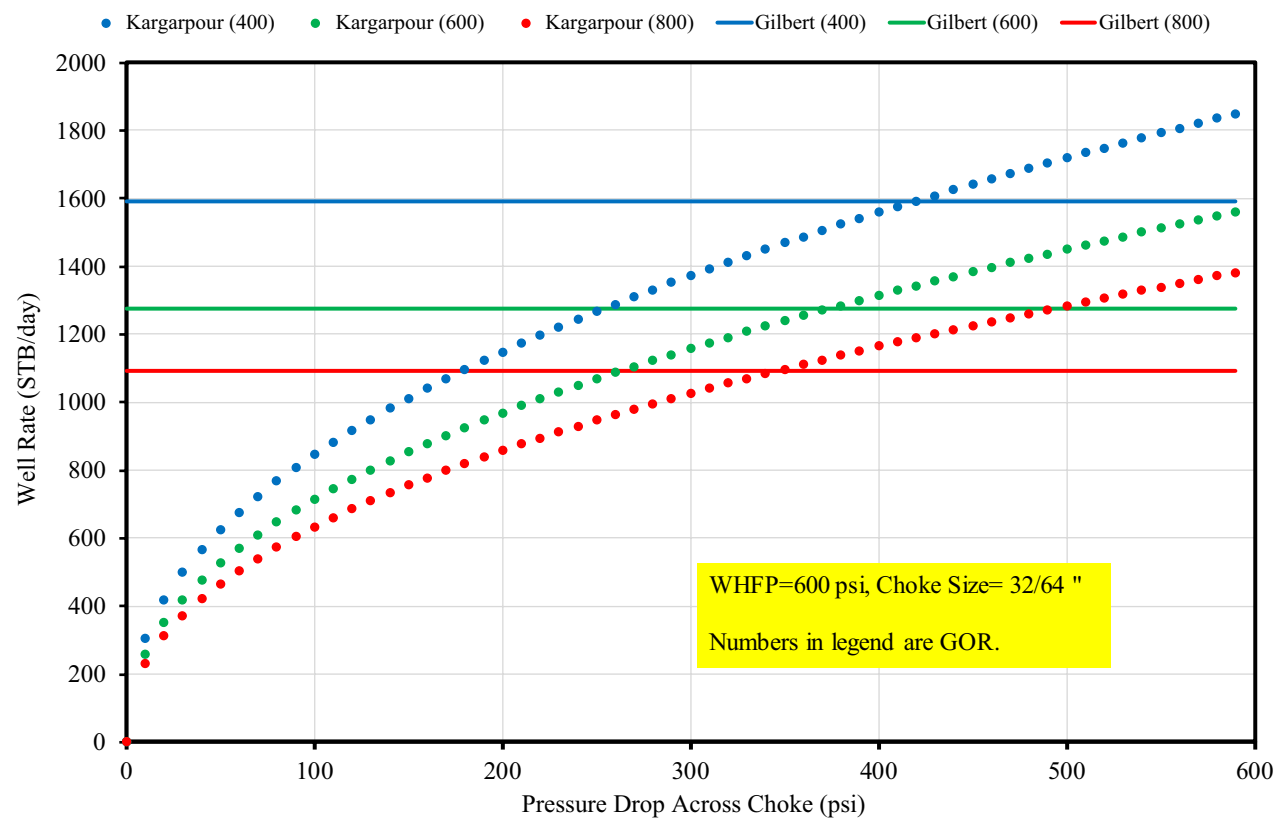

results in one flow rate for the entire range of pressure drop across the choke; however, the new one formula gives a range of flow rate from zero to a maximum value.

One factor which has a great effect on the choke performance is Reynold's number. This factor is ignored in Gilbert-type choke formula for the sake of simplicity. The following Reynolds number is adopted from White (2011):

$R e_{\mathrm{d}}=\frac{V \rho d}{\mu}=\frac{4}{\pi} \frac{\rho q}{\mu d}$,

where ' $R e_{\mathrm{d}}$ ', ' $V$ ', ' $\rho$ ', ' $d$ ', ' $\mu$ ', and ' $q$ ' are Reynolds number based on the choke size diameter, fluid velocity through the choke, fluid density, diameter of choke, fluid viscosity, and flow rate through the choke in consistence units, respectively. Note that velocity, density, and viscosity in Eq. (14) are properties of two-phase fluid, including gas and liquid. Dependency of choke performance to Reynolds number implicitly implies that no unique global simple choke formula can be derived for all range of GOR, oil API gravity, oil and gas viscosities, water cut, flowing well head pressures, and the two-phase flow regimes. So, it means to have more accurate well flow rate estimation by choke formula it is necessary to derive different formulas for different range of flow rates even for a specific reservoir.

\section{Conclusions and recommendations}

Based on the materials presented and discussed in this paper, the following points can be drawn:

a. For low-condensate gas wells, for the estimation of well gas flow rate, use Eq. (5) by employing appropriate con- stant value in range of 19,000-25,000; provided the gas flow through the choke under sonic conditions.

b. For subsonic single-phase gas flow, use Eq. (6).

c. At usual prevailing field flowing well head pressures, having critical (sonic) flow conditions through the well head choke in an oil well is under question.

d. Using basic fluid flow concepts, general choke formulas for estimating two-phase fluid flow through the well head chokes are derived (Eqs. 8 and 9) and validated by field data.

e. Simplified Gilbert-type equation (Eq. 10 or 11) including pressure drop across the choke is derived for twophase fluid flow through the well head choke.

f. No single choke formula can be derived for all flow conditions (of PVT) for two-phase flow.

g. Field engineers are encouraged to derive specific choke formula for the field of interest using Eq. (10) or (11) together with reliable field measurements for certain range of flow rate.

Open Access This article is distributed under the terms of the Creative Commons Attribution 4.0 International License (http://creativeco mmons.org/licenses/by/4.0/), which permits unrestricted use, distribution, and reproduction in any medium, provided you give appropriate credit to the original author(s) and the source, provide a link to the Creative Commons license, and indicate if changes were made.

\section{Appendix 1: choke formula for gases}

Velocity of sound in materials in mathematical form is as (Streeter 1962; White 2011) 
$c=\sqrt{\frac{d p}{d \rho}}$,

where $c, P$, and $\rho$ are sound velocity, pressure, and density, respectively.

Bulk modulus of elasticity is also defined as (Streeter 1962; White 2011)

$B=-\frac{d p}{d v / v}$

$\mathrm{B}$ and $\mathrm{v}$ are bulk modulus of elasticity and volume of fluid subjected to $d p$, respectively. $P$ is pressure, as above.

$\frac{d v}{v}=-\frac{d \rho}{\rho}$,

$\therefore B=\rho \frac{d p}{d \rho}$.

Combine equations (15) and (18); from Equation (18), one can write $\frac{d p}{d \rho}=\frac{B}{\rho}$ and then from Eq. (15):

$c=\sqrt{\frac{B}{\rho}}$.

The process of 'flow through choke' may be considered to be isentropic; so, for gases can be written as

$p \rho^{-k}=$ constan,

where $\mathrm{k}$ is specific heat ratio $(\mathrm{k})$ :

$k=\frac{C_{p}}{C_{v}}=-\frac{d p / p}{d V / V}$.

Take derivative of Equation (20) with respect to $\rho$ :

$\frac{d p}{d \rho}=\frac{k p}{\rho}$.

Insert Equation (22) and in Equation (15):

$c=\sqrt{\frac{k p}{\rho}}$.

By definition, density of gases can be calculated from the following equation (Guo and Ghalambor 2005; Tiab 2000):

$\rho=\frac{P M}{Z R T}$,

where $P, M, Z, R$, and $T$ are gas pressure, (psia); gas molecular weight, (lbm/lbmole); gas compressibility factor, (dimensionless); universal gas constant, $\left(1545.4 \frac{\mathrm{ft.lbf}}{\mathrm{lbmole} .{ }^{\circ}}\right)$; and gas temperature, $\left({ }^{\circ} \mathrm{R}\right)$, respectively.
Combine Equations (23) and (24):

$c=\sqrt{\frac{Z k R T}{M}}$.

For unit consistency use the conversion factor $\left(32.174 \frac{\mathrm{lbm} \cdot \mathrm{ft}}{\mathrm{lbf} . S^{2}}\right.$ ) :

$c=\sqrt{\frac{32.174 \times Z k R T}{M}}$.

Note that by above units, the unit of ' $c$ ' would be ' $\mathrm{ft} / \mathrm{s}$ '.

Let us define gas gravity $(G)$ as (Guo and Ghalambor 2005; Tiab 2000):

$G=\frac{\text { density of gas }}{\text { density of air }}=\frac{\text { molecular weight of gas }}{\text { molecular weight of air }}=\frac{M_{\text {gas }}}{M_{\text {air }}}$.

But molecular weight of air is around $28.97 \mathrm{lbm} / \mathrm{lbmole}$; so,

$M_{\mathrm{gas}}=28.97 G$.

Insert data; Equation (28) and universal gas constant $\left(1545.4 \frac{f t . l b f}{1 \text { bmole. }{ }^{\circ} \mathrm{R}}\right)$ in Equation (26):

$c=\sqrt{\frac{32.174 \times 1545.4 \times Z k T}{28.97 G}}$,

$c=41.4284 \sqrt{\frac{Z k T}{G}}$.

Recall that $c, z, k, T$, and $G$ are sound velocity in gases, (ft/s); gas compressibility, dimensionless; gas specific heat ratio, dimensionless; gas temperature, $\left({ }^{\circ} \mathrm{R}\right)$; and gas gravity, dimensionless, respectively.

By definition at choking condition, the gas velocity would be equal to sound velocity; so, it means that the actual gas flow rate through the bean at choking condition can ideally be calculated by following equation:

$\mathrm{Q}_{\mathrm{acfd}}=24 \times 3600 \times 41.4284 \times \frac{\pi}{4} \times \frac{d^{2}}{144} \times \sqrt{\frac{Z k T}{G}}$,

$\mathrm{Q}_{\mathrm{acfd}}=19523 \times d^{2} \sqrt{\frac{Z k T}{G}}$,

where ' $d$ ' is choke diameter in 'inches'.

From equation of state of real gases, it can be written as

$\frac{P_{s} Q_{s}}{P_{a} Q_{a}}=\frac{Z_{s} R T_{s}}{Z_{a} R T_{a}}$,

where indices ' $s$ ' and ' $a$ ' refer to 'standard' and 'actual' conditions, respectively. By considering the standard conditions as follows, Equation (33) becomes Equation (34):

Standard conditions: $P=14.7 \mathrm{psia}, Z=1.00, T=520^{\circ} \mathrm{R}$. 
$Q_{s}=35.3741 \frac{P_{a}}{Z_{a} T_{a}} Q_{a}$.

Insert Equation (32) in Equation (34):

$\mathrm{Q}_{\text {scfd }}=690,597 \times \sqrt{\frac{1}{z}} \times \sqrt{\frac{1}{T}} \times \sqrt{\frac{k}{G}} \times P d^{2}$.

Equation (35) is the basic equation for estimating single-phase dry gas flow rate through a choke, provided the choking conditions prevail (ratio of pressures of upstream to downstream of choke to be less than about 0.55).

In investigating an equation for calculating fluid flow through any constraint, a phenomenon which is so-called 'vena contracta' should be considered. It is defined as the reduction in the area/diameter of a fluid jet after it emerges from a circular aperture in a pressurized reservoir (White 2011). The combination of this amount plus effect of other factors is called discharge coefficient, $C_{d}$ (Baker 2000). Discharge coefficient is correlated with the ratio of the orifice (choke) diameter to the pipe diameter ( $\beta$ ratio). Therefore, Equation (35) becomes:

$\mathrm{Q}_{\text {scfd }}=690,598 \times C_{d} \times \sqrt{\frac{1}{z}} \times \sqrt{\frac{1}{T}} \times \sqrt{\frac{k}{G}} \times P d^{2}$.

To simplify Equation (36) as much as possible and reduce it to a more familiar gas flow through the choke $\left(\mathrm{Q}_{\text {scfd }}=C P d^{2}\right)$, let us assume logic values for variables of $C_{\mathrm{d}}, Z, T, k$, and $G$.

Heat capacity ratio $(k)$ : Let us consider the average specific heat ratio to be equal to 1.28 (Guo et.al. 2007).

Gas gravity $(G)$ : The chemical composition of natural gas varies widely around the world; however, the natural gas gravity could be considered in the range of 0.6-0.7 (Faramawy et.al. 2016) for engineering purposes. Here, it is supposed that the average gas gravity is about 0.65 .

Temperature (T): In Equation (36), temperature (T) is upstream the choke flowing temperature. The magnitude of this temperature depends on several factors, such as depth of gas reservoir (or better to say gas reservoir's temperature), sand face pressure drawdown, gas production rate, and size of production well string. Here, based on experience and assuming well's producing interval depth would be in the range of 10,000-12,000 $\mathrm{ft}$ from surface, the flowing wellhead temperature is considered to be in the range of $150-200{ }^{\circ} \mathrm{F}$ with average of $175^{\circ} \mathrm{F}$.
Gas compressibility factor: By assuming gas gravity and temperature to be equal to 0.65 and $175^{\circ} \mathrm{F}$, the gas compressibility factor is estimated to be around 0.88 . It is assumed that the flowing upstream choke pressure would be in the range of 1800-2800 psi.

Discharge coefficient: By employing the concept of discharge coefficient in flow measurement by orifice and assuming the choke diameter size to inside pipe diameter ratio to be around $0.1-0.25$, the discharge coefficient is estimated to be around 0.6 (refer to Baker 2000).

Final choke gas flow equation: Based on the above assumptions, Equation (36) will become:

$\mathrm{Q}_{\text {scfd }}=690,597 \times C_{d} \times \sqrt{\frac{1}{0.88}} \times \sqrt{\frac{1}{(175+460)}} \times \sqrt{\frac{1.28}{0.65}} \times P d^{2}$,

$\mathrm{Q}_{\mathrm{scfd}}=40997 \times C_{d} \times P d^{2}$,

$\mathrm{Q}_{\text {scfd }}=24598 \times P d^{2}$.

Variation in assumed values of each parameter of Eq. (36) in the range of 90-110 percent has little effect on the constant of Equation (39). By variation of each parameter in this range, the numerical value of the constant in Equation (39) will vary in the range of $23,368-25,827$.

Equation (39) is for the estimation of single-phase dry gas flow rate through a wellhead's choke provided the gas velocity through the choke device becomes sonic. The condition for sonic velocity through the choke is defined by the following equation (Streeter 1962; White 2011):

$\frac{P_{\text {downstream }}}{P_{\text {upstream }}} \leq\left(\frac{2}{k+1}\right)^{\left(\frac{k}{k-1}\right)} \leq\left(\frac{2}{1.28+1}\right)^{\left(\frac{1.28}{1.28-1}\right)} \leq 0.5494$.

Note that in practical engineering purposes, the constant in Equation (39) is considered to be between 19,000 and 26,000 depends on the gas stream conditions and specifications.

\section{Appendix 2: subsonic choke formula for gases}

The following formula for gas mass flow rate under subsonic conditions is adopted from Streeter (1962):

$\dot{m}=\rho v A=A \sqrt{2 P_{\text {upstream }} \rho_{\text {upstream }} \frac{k}{k-1}\left(\frac{P_{\text {downsream }}}{P_{\text {upstream }}}\right)^{2 / k}\left[1-\left(\frac{P_{\text {downsream }}}{P_{\text {upstream }}}\right)^{(k-1) / k}\right]}$. 
Insert Eq. (24) into Eq. (41):

Appendix 3: choke for liquids

$\dot{m}=A \sqrt{2 P_{\text {upstream }}^{2} \frac{M}{Z R T_{\text {upstream }}} \frac{k}{k-1}\left(\frac{P_{\text {downsream }}}{P_{\text {upstream }}}\right)^{2 / k}\left[1-\left(\frac{P_{\text {downsream }}}{P_{\text {upstream }}}\right)^{(k-1) / k}\right]}$.

In English units and for consistency, apply the conversion factor $\left(32.174 \frac{\mathrm{lbm} \cdot f t}{l b f . S^{2}}\right)$ :
It is not common to use choke for limiting the liquid flow; however, it is interesting to calculate the magnitude of order of

$\dot{m}=\frac{\pi}{4} d^{2} P_{\text {upstream }} \sqrt{2 \times 32.174 \times \frac{0.65 \times 28.97}{0.88 \times 1545.4 \times(460+175)} \times \frac{1.28}{1.28-1} \times\left(\frac{P_{2}}{P_{1}}\right)^{2 / 1.28}\left[1-\left(\frac{P_{2}}{P_{1}}\right)^{(1.28-1) / 1.28}\right](43)}$

In Equation (43), the assumed average values for some variables such as specific heat ratio, upstream choke temperature, gas molecular weight are employed. Simplify Equation (43):

$\dot{m}=0.0629 \times d^{2} P_{1} \sqrt{\left(\frac{P_{2}}{P_{1}}\right)^{1.5625}\left[1-\left(\frac{P_{2}}{P_{1}}\right)^{0.21875}\right]}$,

where $\dot{\mathrm{m}}, P_{1}, P_{2}$, and ' $d$ ' are gas mass flow rate, $\mathrm{lb}_{\text {mass }} / \mathrm{sec}$; flowing upstream choke pressure, psi; flowing downstream choke pressure, psi; and choke size diameter, inches.

By dividing the gas mass flow rate by its density at standard conditions (gas gravity $=0.65$ ) and introducing the discharge coefficient in the above equation, the final choke gas flow rate under subsonic conditions is obtained:

$q_{\mathrm{scfd}}=65554 \times d^{2} P_{1} \sqrt{\left(\frac{P_{2}}{P_{1}}\right)^{1.5625}\left[1-\left(\frac{P_{2}}{P_{1}}\right)^{0.21875}\right]}$.

In above equation with assuming $\mathrm{P}_{2} / \mathrm{P}_{1}$ values equal to 0.6 , 0.7 , and 0.8 , the following equation (45) becomes:

$$
\begin{array}{ll}
q_{\text {scfd }}=14301 \times d^{2} P_{1} & \text { for }\left(\frac{P_{2}}{P_{1}}\right)=0.6, \\
q_{\text {scfd }}=13592 \times d^{2} P_{1} & \text { for }\left(\frac{P_{2}}{P_{1}}\right)=0.7, \\
q_{\text {scfd }}=12019 \times d^{2} P_{1} & \text { for }\left(\frac{P_{2}}{P_{1}}\right)=0.8 .
\end{array}
$$

pressure drop across a device (e.g., choke) to reach the choking conditions; i.e., reaching sonic velocity. Let us start with Eq. (19):

$c=\sqrt{\frac{B}{\rho}}$.

Bernoulli's equation can be used for liquids:

$\frac{P_{\text {upstream }}}{\gamma}+\frac{V_{\text {upstream }}^{2}}{2 g}=\frac{P_{\text {downstream }}}{\gamma}+\frac{V_{\text {downstream }}^{2}}{2 g}$.

Consider that downstream conditions refer to choke throat. Also, for liquids, one can write $A_{1} V_{1}=A_{2} V_{2}$; so, it can be written as

$V_{\text {upstream }}=\frac{A_{\text {choke }}}{A_{\text {pipe }}} V_{\text {downstream }}$.

Combine Eqs. (50) and (51) and simplify:

$$
\begin{aligned}
& \frac{P_{\text {upstream }}-P_{\text {downstream }}}{\gamma}=\frac{V_{\text {downstream }}^{2}}{2 g}\left[1-\left(\frac{A_{\text {choke }}}{A_{\text {pipe }}}\right)^{2}\right], \\
& V_{\text {downstream }}^{2}=\frac{2 \Delta P}{\rho} \times \frac{1}{\left[1-\left(\frac{A_{\text {choke }}}{A_{\text {pipe }}}\right)^{2}\right]} .
\end{aligned}
$$

At choking conditions, $V_{\text {downstream }}=$ Sonic Velosity $=c$; so, Equation (53) becomes:

$\Delta P=\frac{\rho\left[1-\left(\frac{A_{\text {choke }}}{A_{\text {pipe }}}\right)^{2}\right]}{2} c^{2}$. 
Equation (54) is the general form for calculating the required differential pressure across a choke to reach choking condition. Combine Eqs. (49) and (54):

$\Delta P=\left(\frac{B}{2}\right) \times\left[1-\left(\frac{A_{\text {choke }}}{A_{\text {pipe }}}\right)^{2}\right]$.

Ignore the term $\left[1-\left(\frac{A_{\text {choke }}}{A_{\text {pipe }}}\right)^{2}\right]$,

$\Delta P=\frac{B}{2}$.

If ' $\mathrm{B}$ ' (bulk modulus of elasticity) is in psi then the unit of $\Delta P$ will also be in psi. Batzle and Wang (1992) estimated the bulk modulus of elasticity of some crude in the range $217,500-375,000 \mathrm{psi}(1500-2500 \mathrm{MPa})$. It means that to have choking conditions across a choke in single-phase crude oil service, the differential pressure across the choke should be more than hundreds thousands of psi.

\section{Appendix 4: choke for two-phase (gas and liquid) flow}

For two-phase flow through the choke, let us assume that part of area of choke is occupied by gas stream and in the remaining of this area liquid flows. In mathematical form, one can write:

$A_{\mathrm{t}}=A_{\mathrm{g}}+A_{1}$,

where ' $A_{\mathrm{t}}$ ', ' $A_{\mathrm{g}}$ ', and ' $A_{1}$ ' are total choke throat area, assumed area available for gas flow, and assumed area available for liquid flow, respectively.

$\pi \frac{d_{\mathrm{t}}^{2}}{4}=\pi \frac{d_{\mathrm{g}}^{2}}{4}+\pi \frac{d_{1}^{2}}{4}$,

$d_{\mathrm{t}}^{2}=d_{\mathrm{g}}^{2}+d_{1}^{2}$,

where ' $d_{\mathrm{t}}$ ', ' $d_{\mathrm{g}}$ ', and ' $d_{1}$ ' are in internal choke diameter, imaginary choke diameter available for gas flow, and imaginary choke diameter available for liquid flow, respectively.

Insert appropriate relation in right-hand side's terms of Eq. (59):

Use Equation (45) for gas flow:

$d_{\mathrm{g}}^{2}=\frac{q_{\mathrm{scfd}}}{65554 \times P_{1} \sqrt{\left(\frac{P_{2}}{P_{1}}\right)^{1.5625}\left[1-\left(\frac{P_{2}}{P_{1}}\right)^{0.21875}\right]}}$.
For liquid, start from Equation (53):

$$
V_{\text {downstream }}^{2}=\frac{2 \Delta P}{\rho} \times \frac{1}{\left[1-\left(\frac{A_{\text {choke }}}{A_{\text {pipe }}}\right)^{2}\right]} \text {. }
$$

Ignore the term $\frac{1}{\left[1-\left(\frac{A_{\text {choke }}}{A_{\text {pipe }}}\right)^{2}\right]}$ and by considering that the downstream velocity is choke device's velocity and employing the unit consistency factor $\left(32.174 \frac{l b m . f t}{l b f . S^{2}}\right)$ :

$q_{l}=\pi \frac{d^{2}}{4} \sqrt{\frac{2 \Delta P}{\rho}}$,

$q_{l}=\pi \frac{\mathrm{d}^{2} / 144}{4} \sqrt{\frac{2 \times 144 \times \Delta P}{\operatorname{SpGr} \times 62.4} \times 32.174}$.

In Eq. (63), liquid flow rate is in $\mathrm{ft}^{3} / \mathrm{s}, \mathrm{d}$ is choke size diameter in inches, $\Delta P$ is differential pressure across the choke in psi and $\mathrm{SpGr}$ is oil-specific gravity respect to water. Convert the unit of liquid flow rate to barrel per day:

$q_{\mathrm{BPD}}=1022.7 \mathrm{~d}_{l}^{2} \sqrt{\frac{\Delta P}{\mathrm{SpGr}}}$.

As the liquid is not stabilized, let us introduce an average shrinkage factor equal to 0.9 and introduce the discharge coefficient equal to 0.6 :

$q_{B P D}=552 d_{l}^{2} \sqrt{\frac{\Delta P}{S p G r}}$,

$d_{l}^{2}=\frac{q_{B P D}}{552 \sqrt{\frac{\Delta P}{S p G r}}}$.

Insert Eqs. (66) and (60) in Eq. (59):

$d_{t}^{2}=\frac{q_{B P D}}{552 \times \sqrt{\frac{\Delta P}{S p G r}}}+\frac{q_{s c f d}}{65554 \times P_{1} \times \sqrt{\left(\frac{P_{2}}{P_{1}}\right)^{1.5625}\left[1-\left(\frac{P_{2}}{P_{1}}\right)^{0.21875}\right]}}$,

$d_{t}^{2}=\frac{q_{B P D}}{P_{1}}\left\{\frac{P_{1}}{552 \times \sqrt{\frac{\Delta P}{S p G r}}}+\frac{G O R}{65554 \times \sqrt{\left(\frac{P_{2}}{P_{1}}\right)^{1.5625}\left[1-\left(\frac{P_{2}}{P_{1}}\right)^{0.21875}\right]}}\right\}$,

or

(68) 
$q_{B P D}=P_{1} d^{2} \times\left\{\frac{P_{1}}{552 \times \sqrt{\frac{\Delta P}{S p G r}}}+\frac{\text { GOR }}{65554 \times \sqrt{\left(\frac{P_{2}}{P_{1}}\right)^{1.5625}\left[1-\left(\frac{P_{2}}{P_{1}}\right)^{0.21875}\right]}}\right\}^{-1}$.

Insert $\Delta P=P_{1}-P_{2}=P_{1}\left(1-\frac{P_{2}}{P_{1}}\right)$. in Eq. (69):

$q_{B P D}=P_{1} d^{2} \times\left\{\frac{\sqrt{P_{1}}}{552 \times \sqrt{\frac{\left(1-\frac{P_{2}}{P_{1}}\right)}{S p G r}}}+\frac{\mathrm{GOR}}{65554 \times \sqrt{\left(\frac{P_{2}}{P_{1}}\right)^{1.5625}\left[1-\left(\frac{P_{2}}{P_{1}}\right)^{0.21875}\right]}}\right\}^{-1}$.

Equation (70) is general form of choke formula for estimating the liquid flow rate in two-phase fluid flow.

\section{References}

Achong I (1961) Revised bean performance formula for lake maracaibo wells. Shell internal report, Oct. 1961

Al-Attar HH (2010) New correlations for critical and subcritical twophase flow through surface chokes in high-rate oil wells. Paper SPE-120788-PA. https://doi.org/10.2118/120788-PA

Al-Attar HH, Abdul-Majeed GH (1988) Revised bean performance equation for east baghdad oil wells. Paper SPE-13742-PA. https ://doi.org/10.2118/13742-PA

Ashford FE, Pierce PE (1974) The determination of multiphase pressure drops and flow capacities in downhole safety valves. JPT, September 1975, p 1145

Bairamzadeh S, Ghanaatpisheh E (2015) A new choke correlation to predict liquid flow rate. Journal of Science International (Lahore) 27(1):271-274

Baker RC (2000) Flow measurement handbook, industrial designs, operating principles, performance, and applications. Cambridge University Press, Cambridge

Batzle M, Wang Z (1992) Seismic properties of pore fluids. Geophysics 57(11):1396-1408

Baxendall PB, Thomas R (1961) The calculation of pressure gradients in high-rate flowing wells. J Petrol Technol, 13:1-023

Beiranvand MS, Mohammadmoradi P, Aminshahidy B, Fazelabdolabadi B, Aghahoseini S (2012) New Multiphase Choke Correlations for a High Flow Rate Iranian Oil Field. Mechanical Science 3:43-47. https://doi.org/10.5194/ms-3-43-2012. 2012.

Brill JP, Mukherjee H (1999) Multiphase Flow in Wells. Society of Petroleum Engineers, Inc., Richardson, 1999

Buffa FK, Baliño JL (2017) Review of Multiphase Flow Models for Choke Valves. IV Journeys in Multiphase Flows (JEM2017), March 27-31, 2017-São Paulo, Brazil

Elgibaly AAM, Nashawi IS (1997) Critical Two-Phase Flow Through Wellhead Chokes of Middle-East Oil Wells. IN SITU 21(4):395427 (1997)

Faramawy S, Zaki T, Sakr AA (2016) Natural gas origin, composition, and processing: A review. J Nat Gas Sci Eng 34(2016):34-54, Elsevier
Fortunati F (1972) Two-Phase Flow Through Wellhead Chokes. Paper SPE 3742

Ganat TA, Hrairi M (2018) A New Choke Correlation to Predict Flow Rate of Artificially Flowing Wells. J Petrol Sci Eng 171(2018):1378-1389

Giacchetta G, Leporini M, Marchetti B, Terenzi A (2014) Numerical Study of Choked Two-Phase Flow of Hydrocarbons Fluids through orifices. J Loss Prev Process Ind 27(2014):13-20

Gilbert WE (1954) Flowing and gas-lift well performance. API Drilling Production Practice 20(1954):126-157

Guo B, Ghalambor A (2005) 'Natural Gas Engineering Handbook', Gulf Publishing Company, Houston

Guo B, Lyons WC, Ghalambor A (2007) Petroleum production engineering, a computer-assisted approach. Elsevier Science and Technology Books, Amsterdam

Perkins TK (1993) Critical and Subcritical Flow of Multiphase Mixtures Through Chokes. Paper SPE 20633. https://doi. org/10.2118/20633-PA

Rastoin S, Schmidt Z, Doty DR (1997) A Review of Multiphase Flow Through Chokes. J Energy Res Technol 119(1):1-10 (Mar 01, 1997). https://doi.org/10.1115/1.2794216

Ros NCJ (1960) An analysis of critical simultaneous gas/liquid flow through a restriction and its application to flow metering. Appl Sci Res 9(Series A):374

Sachdeva R, Schmidt Z, Brill JP, Blais RM (1986) Two-phase flow through chokes. Paper SPE 15657 MS

Sadiq DJ (2012) Predication of oil flow rate through choke at critical flow for iraqi oil wells. J Pet Res Stud 212:53-79

Streeter VL (1962) Fluid Mechanics. In: McGraw-hill book company, inc., international student edition, 3rd edn. Kogakusha Company, LTD., Tokyo

Tangren RF, Dodge CH, Seifert HS (1949) Compressibility effects in two-phase flow. J Appl Phys 20:637-645 (1949). https://doi. org/10.1063/1.1698449

Tiab D (2000) 'Gas reservoir engineering', lecture notes, Summer University 2000

White FM (2011) Fluid Mechanics, 7th edn. McGraw-Hill, New York

Publisher's Note Springer Nature remains neutral with regard to jurisdictional claims in published maps and institutional affiliations. 